\title{
Location-based Photography as Sense-making
}

\author{
Chris Baber \\ EECE \\ The University of \\ Birmingham \\ Birmingham. UK \\ 00441214143965

\section{c.baber@bham.ac.uk}

\author{
Tariq Khaleel \\ EECE \\ The University of \\ Birmingham \\ Birmingham. UK \\ 00441214143965
}

\author{
Russell Beale \\ Computer Science \\ The University of \\ Birmingham \\ Birmingham. UK \\ 00441214143729
}

\begin{abstract}
In this paper we consider ways in which images collected in the field can be used as to support sense-making. Weick's concept of sense-making is applied to the capture of images. A study is reported in which visitors to an open-air museum were asked to take photographs of aspects of the site that they found interesting. Photographs were taken using a bespoke application in which a webcam and global positioning system device, attached to a small tablet computer, are used to capture tagged images. Tagging is supported by the use of a simple menu that allows users to classify the images.
\end{abstract}

\section{Categories and Subject Descriptors}

\section{H.5.2 User Interfaces; H.1.2 User/ Machine Systems; C.5.3 Microcomputers}

\section{General Terms}

Design, Experimentation, Human Factors.

\section{Keywords}

Digital imaging, Mobile computers, Photography, Sensemaking.

\section{INTRODUCTION}

This paper represents part of a long-term study into the question of how people might use photographs to support sense-making. In particular, we consider ways in which images can be tagged at the point of capture and ask how this might contribute to developing a sense of place during a visit to an open-air museum. The experiment reported in this paper required participants to take photographs that they thought could be used as the basis for subsequent discussion between the visitor and the museum curator. Thus, we require an intentional aspect to photography in that the content of the image can be assumed to have some semantic content in addition to the, perhaps, more conventional notion of photograph as image. However, as we discuss in section 2 , the notion of photography solely for the purpose of capturing an image is not necessarily an adequate

(c) The Author 2008.

Published by the British Computer Society description of 'tourist photography'. The point at issue is what the photograph might mean and how this meaning might be used subsequently for the purposes of interpreting a scene or recalling situations. It our contention that these activities, i.e., interpretation and recall, are central to notions of sense-making. Thus, there could an interesting and important role for photography for collective sense-making relating to an environment or an event. In the long-term we view this work as having a potential bearing on the gathering of information relating to critical incidents, disasters and other emergencies in which members of the public could be on the scene and could provide information to the emergency services. However, for the purposes of this paper we explore the concept with the more homely example of tourism.

Before considering the uses of photography by tourists, we briefly consider how images might be tagged. There are several reasons why one might wish to tag images, although the most common relate to the storage of images in structured databases to support retrieval [11] [13] [23]. The image retrieval community has been exploring means by which images can be manually tagged and, up until quite recently, the general assumption has been that people dislike providing tags to images because it can be so time-consuming. However, if one looks at the images on sites like Flickr, it is apparent that people are prepared to provide minimal annotation to images [10] [16] [17]. As van House [20] points out, image sharing in Flickr provides a means of presenting a 'narrative' of everyday life to family and friends [20]. This use of images has, in some cases, replaced 'blogging' as means of updating the wider world on a person's activity [6]. In this case, the sharing of images can be considered a form of reportage with the aim of producing a set of images that provide a 'sense' of the person's life (as opposed to a photographs that might be considered in more aesthetic terms). This suggests that users could be prepared to provide tags for images if this is seen as contributing to the reportage to which the images contribute. In other words, this activity relates to what Sontag [19] refers to as 'photography-as-science', i.e., compiling an inventory of the world through the use of images. Such activity is, of course, quite different from other approaches to the capture and use of images, and potentially relies not only on the capture of images but also their sharing with many other people. Assuming that many people carry their mobile telephones with them almost all of the time, it can be easy to capture images in all manner of contexts, e.g., teenagers capturing images of their friends at a party and the posting of these images of social networking sites. Digital photography provides people with the opportunity to capture more than the image, through the use of meta-data. This is becoming increasingly possible with the growing sophistication of 
cameras on mobile telephones. Thus, we assume that the tagging of images can be done once the image has been captured (as implied above), or as something that can be done when the image is captured. Tagging images at capture could be performed manually by the user, e.g., by selecting specific descriptors for the image, or automatically, e.g., by some form of context-awareness. This paper uses a combination of these approaches in a simple prototype.

It is feasible that one can define a metadata schema that allows specific features of an image to be automatically tagged, e.g., using CellID, date, time and UserName [22]. This does not provide information on the content of the image, but could provide the basis for linking individuals who have captured images at a given location. Work by Davis and colleagues [8] [18] illustrates how semantic tags can be used to translate the 'context' of capture (defined by location, time and presence of other Bluetooth enabled devices which is used to indicate the presence of device owners when the image was captured) to define the 'content' of the image. By combining these metadata it is possible for images to be categorised and their content interpreted, in terms of commonality of location and device owners [1]

These studies of automatic tagging of images relate to previous work on the use of 'context-awareness' to trigger image capture. The use of 'context' to initiate image capture has been demonstrated by several projects; most notably in Healey and Picard's [12] 'StartleCam', in which changes in galvanic skin response (GSR) was used to trigger image capture; other uses of 'context' in image capture have explored the use of ambient sound which is captured at the same time as the image (e.g., [9] [15]). In previous work [5], we used a set of context identifiers to take still images when 'context' (as defined by GPS location and accelerometer data) changed, and showed that these could be surprisingly consistent with photographs taken by humans, i.e., people took photographs in similar locations to those captured automatically, and the justification given by people could be aligned with the 'context-markers' that were applied. There were obvious differences in the composition of the photographs (the automatic system simply relied on the camera mounted on the wearer's hat and there was no attempt to 'frame' the image) whereas the people attempted to compose a photograph. We had asked people to capture an image when it seemed an appropriate indication of what they were doing, and had designed a context-aware application which captured an image when some aspect of 'context' had changed. This raised the question of how people compose photographs as a means of making sense of their surroundings (the task we had set was to produce a report describing a journey around the University campus).

In subsequent work, we have annotated images with location (based on GPS) and bearing (from digital compass) and descriptions based on simple ontologies of object types [7]. In this way, the act of capturing the image involves tapping a button on the small tablet computer we use so that the image is captured and tagged simultaneously. Thus, the capture of tagged images and prototype devices and applications to support this have an established pedigree. Our interest lies less in the technology and more in the question of how such technology might support human activity.

\subsection{Why do people take photographs?}

We begin with making a distinction between 'tourist photography' and 'creative photography'. The latter refers to photographs taken by either professional photographers or enthusiasts who wish to produce interesting, original and wellcomposed images. The former refers to photographs taken while on holiday, or during other leisure pursuits, which are intended to reflect the experience of the person on holiday. Obviously, this distinction need not be mutually exclusive, but it does suggest that much 'tourist photography' represents a special form of image capture.

Previous studies suggested that the point of a tourist photograph is not the original image so much as the reproduction of images that have already been seen. "What is sought for in a holiday is a set of photography images, which have already been seen in tour company brochures or on TV programmes." ([19], p. 129). One implication of this idea is that there might be specific locations from which photographs can be taken, e.g., some sites might include signs that indicate 'good' vantage points for taking photographs. One reason for the use of these signs is to support a common set of photographs, i.e., with visitors being able to capture images from the 'best' locations. From the point of view of this paper, this raises two issues. First, it is feasible for the physical signs to be replaced by a digital representation, e.g., the GPS coordinates of a specific location and an indication of the appropriate bearing to take a recommended photograph. This introduces the hypothesis that visitors to an open-air museum are likely to take similar photographs from similar locations. Second, the idea that there can be a common set of photographs for people suggests that the scene can be made sense of through such a common set. This introduces the hypothesis that people will take photographs of the same objects and scenes for the same purposes. This is not to imply that people might wish to take other, more original or personal images, but does suggest that some visitors to some sites might prefer to have their decisions on where to take photographs supported by other means.

Larsen [14] proposes that while some aspects of tourist photography are concerned with this reproduction of a common set of images, there is also a performance element in tourist photography, i.e., "Tourist photography is made less visual and more embodied, less concerned with spectatorship and 'consuming places' than with producing place myths, social roles and social relationships, such as family life." ([14] p. 417). His view is of photography being more about the performance of taking a photograph than the representations that are produced. These performances involve not only posing for the camera but also choreographing the shots to be taken in terms of what the act of taking the photograph will signify. Our interpretation of Larsen's study is that the act of taking a photograph can be considered akin to sense-making as defined by Weick [21] in that the process of taking the photograph (and the memories of this) can be as important as the product of the photograph.

\subsection{Weick's Concept of Sense-making}

Weick [21] defined sense-making as a process that could be characterised by seven properties. While these properties were originally intended for the description of organisational behaviour, we feel that they can be translated to this study, as shown below (terms in italics taken from Weicke, [21] p.17):

1. Grounded in identity construction - the actor's behaviour is influenced by the role that they assume in the activity, e.g., whether the 'photographer' considers herself to be an expert or how the 'photographees' are posing for the camera. From this, one might further distinguish the act of taking a photograph as being the creation of a 'product' (a good photograph) or the management of a 'process' (a photograph that captures something happening). In this paper, participants were encouraged to view their photographs as being part of an information-gathering activity; 
2. Retrospective - the sense-making process results in narratives that can be used to justify decisions, actions and communicated information, e.g., how the photographs are not only taken to capture the presence of tourists in a particular place but also how these photographs might be used later to help tell the story of the holiday or to provide cues for reflection or subsequent information search;

3.Enactive of sensible environments - actors respond to specific features of the environment because these features draw their attention through their conspicuity, their design or through the actor's expectations, e.g., capturing particular aspects of the location;

4. Social - sense-making is, by definition, a social process that involves the exchange and elaboration of information, e.g., in terms of deciding where and how to pose for the photographs. In this study, the social aspect was related less to the capture of the image and more to the notion that it would be used as the basis for subsequent discussion;

5. Ongoing - sense-making, as a process, is dynamic, e.g., in terms of a sequence of photographs taken during the course of a holiday or series of holidays;

6. Focused on and by extracted cues - in addition to being performed in a specific environment, sense-making involves the deliberate extraction of information, e.g., the placing of people in the photographs can be used to not only provide an record of the visit but also add 'interest' to the scene;

7.Driven by plausibility rather than accuracy - the goal of sense-making is to achieve an appropriate consensus on the situation, e.g., to construct images that can be used as the basis for recounting the visit to a particular place.

A point of departure from Weick's work lies in our focus on images rather than purely verbal descriptions. Weick assumed that sense-making had a strong narrative element and involved the construction of a shared 'story' to account for events and situations. We agree that this construction of shared 'narrative' is crucial to sense-making but wonder whether the collection of images can be made to serve a similar purpose, i.e., whether the submission of images (albeit tagged with metadata) can be sufficient to create a shared 'story' of an event that reflects the understanding of those involved.

In a previous work, we explored ways in which technology can be used to support shared awareness amongst crime scene examiners. As part of this work, we explored the ways in which 'narratives' (i.e., different accounts from different actors) were constructed and passed through the examination process [2] [3].

\section{CASE STUDY}

We had the opportunity to collect photographs taken by visitors to an open-air museum as part of a study into tourist information technologies. The 'tourist information technologies' study was concerned with the use of virtual and augmented reality as a means of developing tour-guides for visitors (either mobile or located in kiosks on the site). As part of the requirements gathering for this project, we asked participants to take photographs of interesting aspects of the site with the incentive that we would then supply them with information relating to these selected aspects.

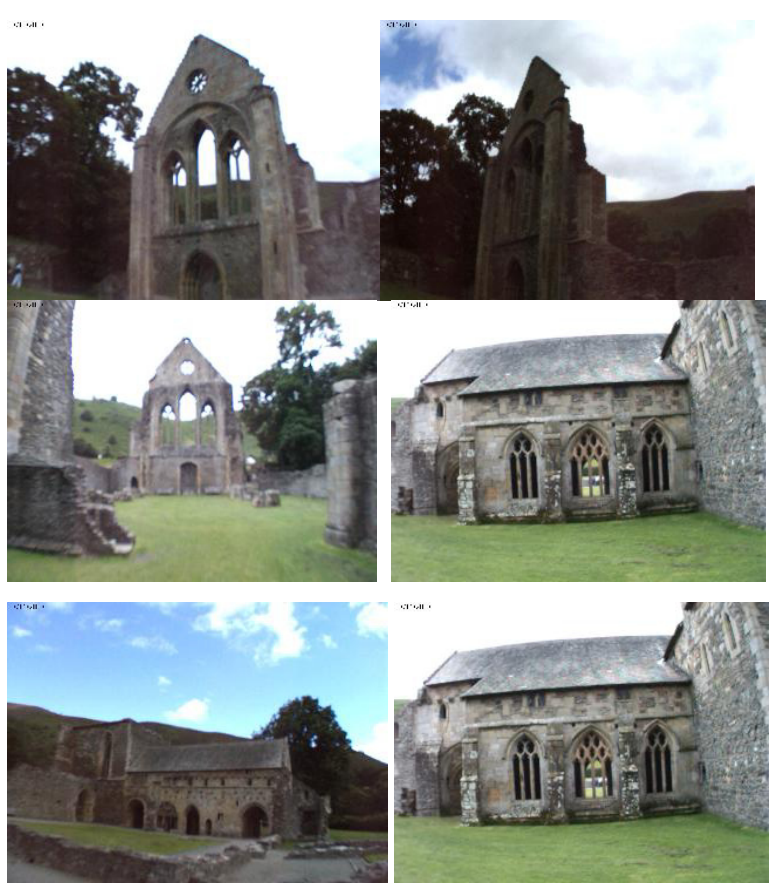

Figure 1: Images of Valle Crucis Abbey (from the study)

\subsection{Location and Participants}

The study took place over two weekends at Valle Crucis Abbey near Llangollen in Powys. As figure 1 illustrates, the Abbey (built around 1200) has fallen into disrepair, partly as a result of the dissolution of the monasteries (Valle Crucis was dissolved in 1537) and partly as a result of the abandonment of the site (and the subsequent removal of masonry to local farms and villages). The site itself was used as a farm in the $18^{\text {th }}$ Century and renovations began in mid $19^{\text {th }}$ Century.

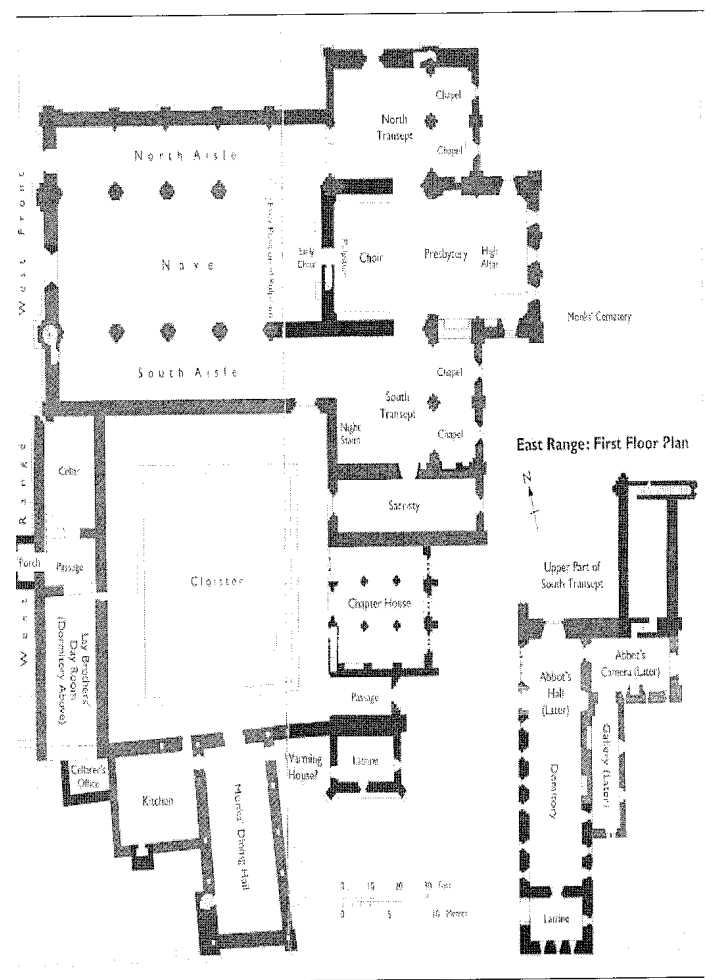

Figure 2: Ground plan of the Abbey site 
The site contains a number of rooms around the large chapel and cloister area, as illustrated by the ground plan in figure 2 . The layout of the abbey follows a ground plan that is common in Cistercian abbeys, with a church that would be used by both choir monks (whose life would be spent in prayer and contemplation) and lay brethren (who would work in the abbey and its grounds). The church would have been divided between these two groups, with the choir monks worshipping in the choir and the chapels and the lay brethren worshipping in the nave. The monks and lay brethren would also have had separate sleeping and dining areas.

\subsection{Equipment}

The study employed a modified version of the application reported in [3]. Images a captured on a webcam attached to a tablet computer. The location of the user is captured using a Global Positioning System (GPS) receiver and the orientation is recorded using a magnetic compass. All of these devices are connected to the tablet via Universal Serial Bus (USB) and their data read into a VisualBasic.net application running on Windows XP. The application runs on a Samsung Q1 tablet. The tablet has a touch-screen that can be interacted with using a pen or fingertips. We have found that people can activate the on-screen buttons reliably using their fingers (see figure 3 ).

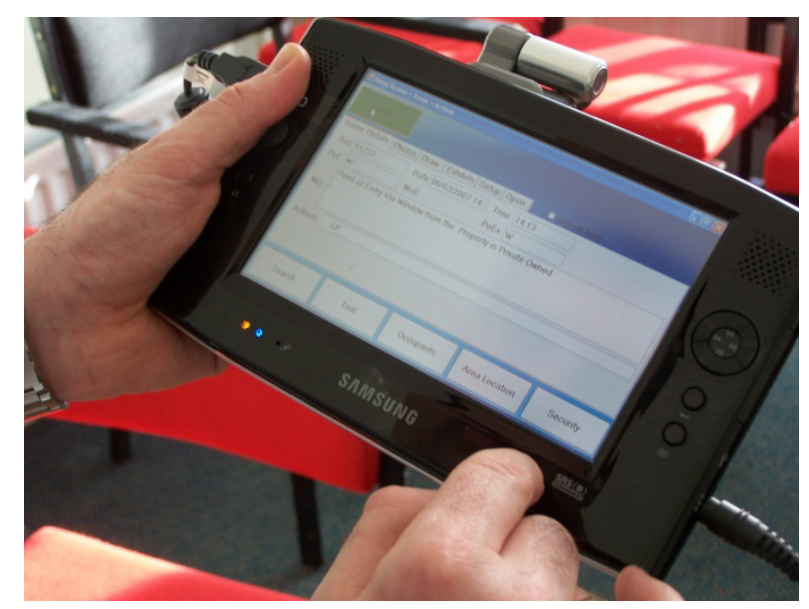

Figure 3: Samsung Q1 tablet running the application. The webcam is located on the top of the device. The screen shows a history of logged images

In order to take a photograph, the user selects one of five classification buttons. Figure 4 shows a screen with classification buttons on the bottom of the screen. The labels on these buttons can edited to suit the application. For the purposes of the study in this paper, they read \{Details, Feature, Appearance, Function $\}$. This meant that the users would be required to describe the reason for taking the photograph. The button label, together with GPS and compass readings were saved as XML tags to the images.

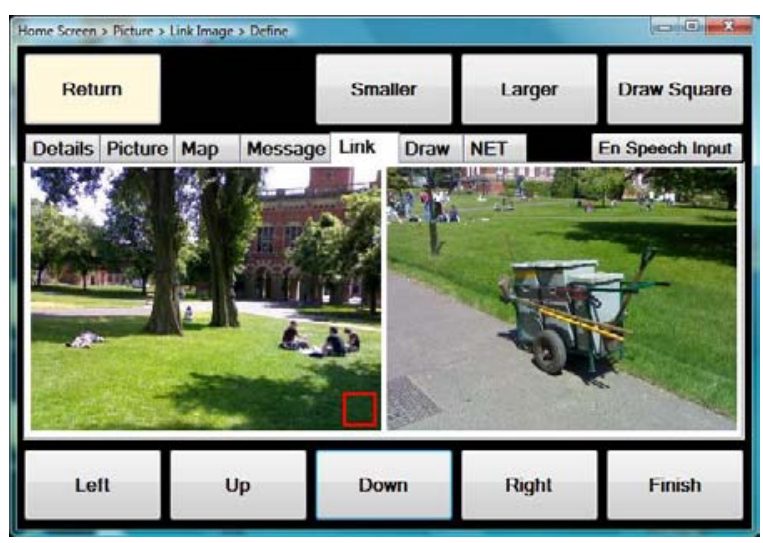

Figure 4: Screen Layout

\section{Procedure}

Participants were recruited on the basis of opportunistic sampling of visitors to the Abbey over the course of two weekends. There were approximately 50 visitors to the site over this period, and 20 were approached and asked to participate. When a visitor entered the Abbey, one of the experimenters approached them and asked if they would be interested in participating in a 20 minute study. The study was described as a test of a new camera concept and, in return for participation, the person would be sent all images they had collected. The 'camera concept' was described as 'allowing you to ask questions by taking photographs'. If the person expressed an interest then a more detailed description of the study was provided, i.e., in terms of the equipment to be used, the nature of the 'classification' task and the requirement to complete a post-trial survey. If the person was still interested then a consent form was signed ${ }^{1}$. In total 16 people agreed to participate (although the data from one person was over-written, so we had data from 15 participants). All of the participants were adults, with a mean age of 52 years, and 12 of the participants were male. While this self-selecting, opportunistic sample represents a fairly homogenous population, we felt that it represented a reasonable sample of the visitors to the Abbey. When asked why they were visiting the Abbey almost all of the participants $(12 / 15)$ stated that they were interested in history and keen to look at the ruins of a medieval Abbey.

The first task for the participant was a familiarisation activity in order to get used to the handling of the tablet PC, the camera and the screen buttons. This simply involved the experimenter supervising a period of trial-and-error learning by the participant, with feedback and advice to correct any misuse or misunderstanding. This took approximately 5 minutes (with a maximum of 7 minutes for one person who then decided that they did not wish to continue the study).

The second task was to 'walk around the Abbey, photographing anything that you find interesting or about which you would like to know more information'. The goal of this task was to have people take photographs that could form the basis of subsequent discussion; in other words, the capture of images was assumed to have an impact on making sense of the site and its contents.

\footnotetext{
${ }^{1}$ The consent form set out the aims of the study and informed the participant of the conditions under which they were participating. This form is used to satisfy the University ethics committee that studies are conducted in accordance with the British Psychological Society's guidelines on ethics.
} 
Following this session, the photographs were shown to the Curator who was able to provide responses to the questions, which were then emailed to the participants together with their photographs. Thus, the 'reward' for participating in the study was a set of photographs taken at the scene, together with information relating to each photograph.

The log files were checked to ensure that the images had been captured together with their metadata (GPS, bearing, labels) and these were saved to file on the tablet and also on to a memory stick.

\subsection{Data and Analysis}

Each photograph's metadata was analysed in terms of Location (defined by GPS and compass readings) and Label (defined by the on-screen button that the person had selected). This provided an analysis of the relative distribution of locations and type of images being collected.

\section{RESULTS}

From the 15 participants in the study, there was a total of 143 unique images for analysis. There was a mean of 9.5 images per person over the 20 minute trial - although one person produced 14 images and another produced 7, the majority of participants took 9 images (seven people) or 10 images (four people).

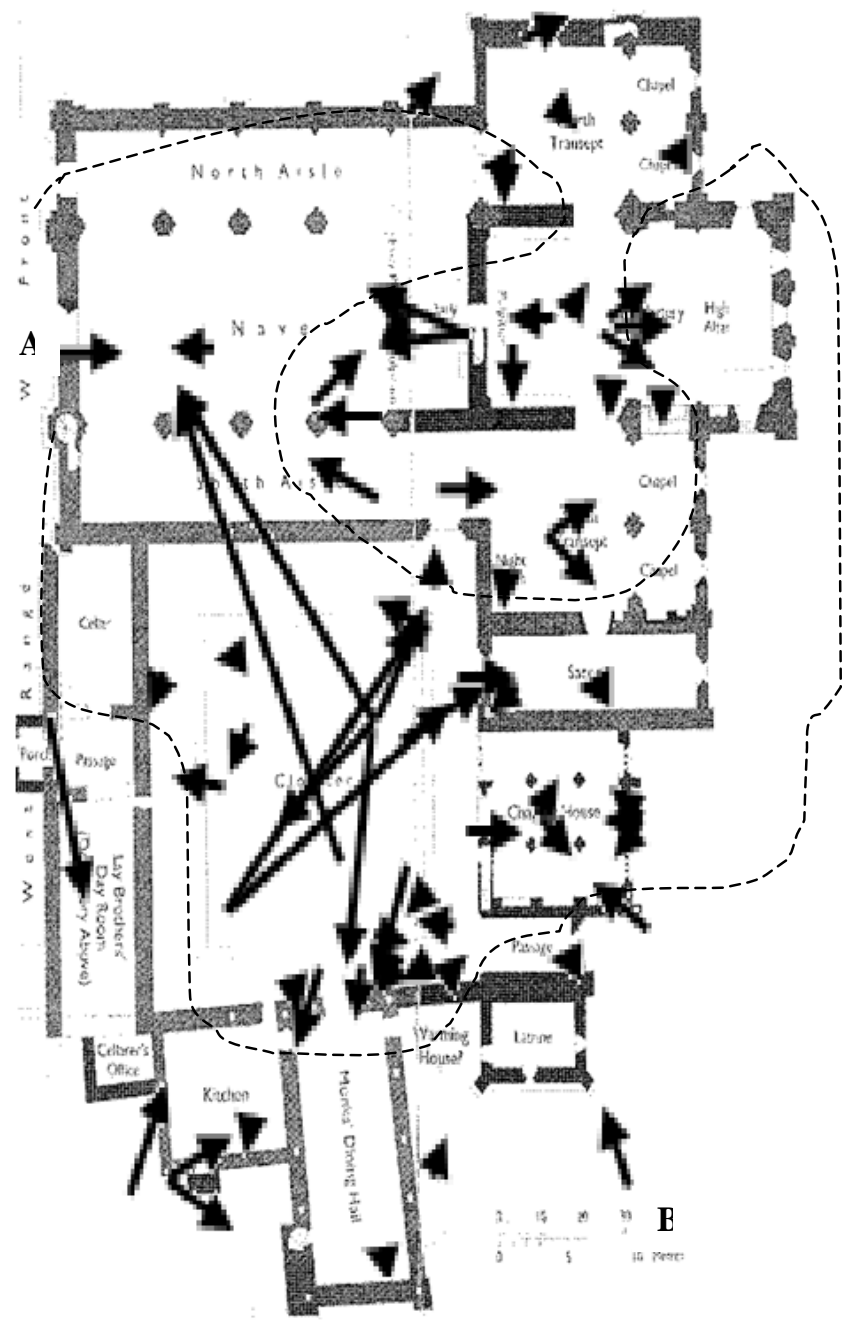

\subsubsection{Location}

The definition of location was based on GPS data, which indicated where the person stood and which direction they were facing when the images were captured. One idea would be to use these data to cue future image capture. We will discuss this further in the discussion section.

The locations were classified in terms of the percentage of total images captured. This leads to four groups:

1. $54 \%$ Inside of building structures ( $10 \%$ for hall; $5 \%$ each for dormitory, south transept, dining hall, camera, choir, sacristy; $3 \%$ each for nave, north transept, presbytery).

2. 20\% - Areas around the central Cloister and Chapter House. These are situated in the centre of the Abbey.

3. $16 \%$ External to the Main Building (16\%) - images of the surrounding countryside or the grounds of the Abbey, perhaps as a way of setting the scene. The majority of these images were taken from one of two locations, i.e., indicated by $\mathrm{A}$ and $\mathrm{B}$ on figure 3 .

4. $10 \%$ other locations. These were typically related to specific features, e.g., graves located to the north-east of the North Transept.

It is interesting to note such a commonality of location for the capture of these images. One implication of this is that it might be possible to cue information provision at these specific locations, knowing that the 'typical' visitor is likely to stand in one of a small number of locations, facing a particular direction and asking a particular question.

What is not apparent from the arrows in figure three is that most participants walked the site in an anti-clockwise manner. This is shown by the dotted line on figure 3 . One might speculate that there is a relationship between the majority of the images captured and the changes in path being followed. In other words, people tended not to stop and take photographs when they were walking in a straight line from one location to another, but would turn and walk in a different direction having taken a few photographs from this location. This implies that the walk around that site was being managed to allow the person to move towards 'good' sites for photography, or that the act of photography was a termination for the walk from one location to another and signalled the start of a new walk.

\subsubsection{Images Captured}

While space limits the presentation of all of the images captured, it is worth looking at a selection of images in terms of their content and the relationship between image and location. This will show some of the interesting consistency in the images that the participants produced. The location data indicated that people stood in approximately similar locations. This can also be seen in the framing of the images, which contain similar features.

Figure 5: Indication of locations and orientation of photographs 

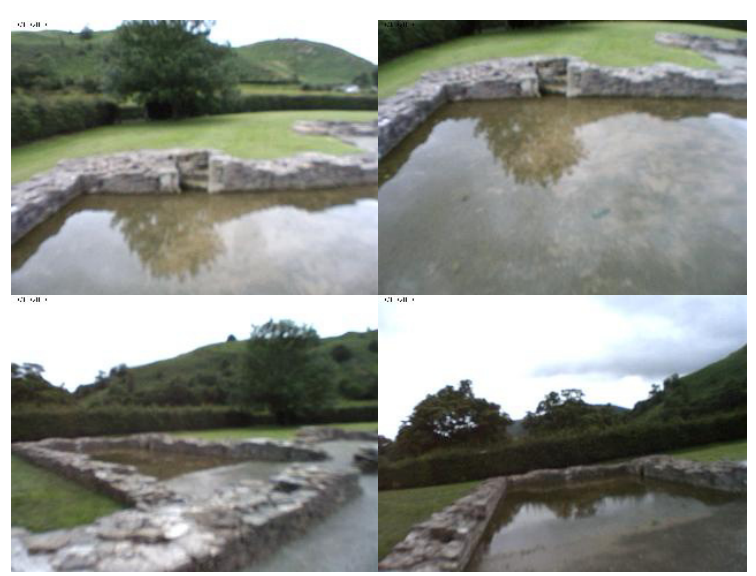

Figure 6: Images of the Monk's Dining Hall

While there are differences in the orientation of the image (and variation in water-level due to the rain on the second weekend) the images are not dramatically different. They all focus on the foundations of the Monk's Dining Hall and were, for the most part, prompted by the question 'What was this room?' This implies that some of the images captured were intended for use as prompts for latter discussion about the 'ruins'. One might say that these images are, perhaps, less well-framed that those which focus on specific features (see table two) in that the goal in taking these images was the question being asked rather than the composition of the image. These images were categorised as Function.

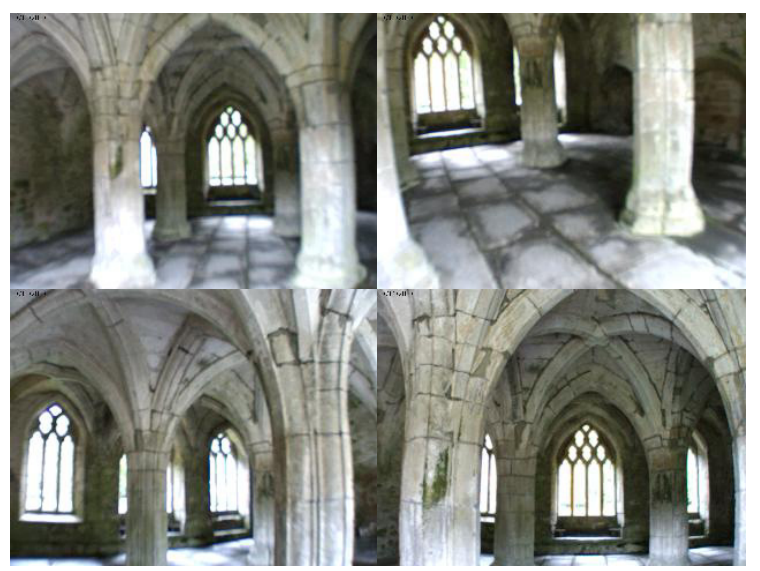

Figure 7: Images captured facing South in South Transept

The images in figure 7 were taken to ask the question 'What did that (possibly stained-glass) window look like?' These images appear to share the common goal of framing the central window by the pillars. One explanation of this is that the presence of a physical object, such as a window or door way, helps to frame the photograph in order to provide a reasonable composition. These images were categorised as Appearance.

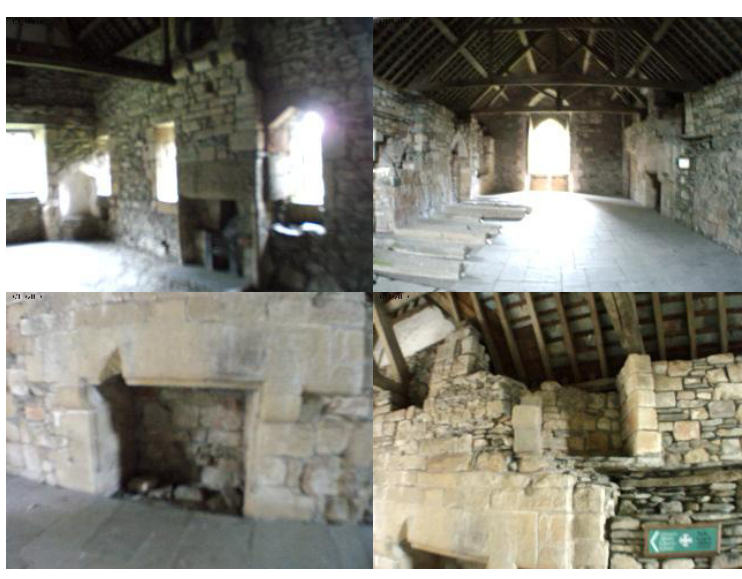

\section{Figure 8: Images of the Fireplace}

The images, taken in the first floor dormitory, in figure 8 were prompted by ask the question 'Why is the stone on the fireplace mantle different to the surrounding stone?' Again the images are not necessarily well-framed but serve as a reminder to the person taking the photograph to ask a specific question. These images were categorised as Details.

One implication of this brief review of photographs was that the categorisation of Appearance seemed to encourage better composition of the images than the categorisation of Function and Details (images categorised as Feature tended to be a mixture of both well- and ill-composed images). This might suggest that capturing an image to ask about the Appearance of something would imply an effort to compose the image such that the object in question was well-framed, whereas capturing the image to prompt a question might imply less focus on composition (because the image would be used as the basis for subsequent discussion).

When questioned after taking the photograph as to their main intention for the image, participants indicated a specific aspect of the building on 84 of 143 , i.e., $58.7 \%$ of occasions. This supports the notion, from the sense-making description, that the activity was 'enactive of sensible environments' and 'driven by and from extracted cues'. Thus, one might suggest that the role being enacted was not of a tourist photographer per se and more of a recorder of the scene. To this end, one might suggest that the taking of photographs had a deliberate objective of preserving details of the visit in order to support subsequent examination and sharing of information.

Table 1: Number of Descriptions mentioning specific objects

\begin{tabular}{|l|c|}
\hline Object & Number \\
\hline room & 22 \\
\hline Window / windows & 12 \\
\hline $\begin{array}{l}\text { \{arches, dining room, features, front door, } \\
\text { house, kitchen, passage, ruin, second floor, } \\
\text { surroundings / view, wall, }\end{array}$ & 12 \\
\hline door & 10 \\
\hline staircase / stairs / stairway & 8 \\
\hline Stone / stonework & 6 \\
\hline grave & 5 \\
\hline Fireplace & 4 \\
\hline building & 3 \\
\hline$\{$ features of window, hole, roof $\}$ & 2 \\
\hline & 84 \\
\hline
\end{tabular}


The remaining $40 \%$ of images were described in terms either of the environment surrounding the Abbey or without reference to a specific aspect, e.g., "how did the Monks spend their day?"

\subsubsection{Categorisation}

Some of the images were captured more than once in order to allow the person to apply more than one categorisation. For example, a stone window frame with a gothic arch was captured twice by one person - once with the category 'appearance' (because he would have liked to have seen the stained glass that might have been in the window) and once with the category 'details' (because he wanted to know if the window was part of the Lay brother's or Monk's chapel).

Table 1: Distribution of Categorisation Descriptors

\begin{tabular}{|l|l|l|l|}
\hline Category & Definition & Total & \% \\
\hline Function & $\begin{array}{l}\text { Asking about the function } \\
\text { of a room or object }\end{array}$ & 46 & 30 \\
\hline Appearance & $\begin{array}{l}\text { How the building might } \\
\text { have looked in the past }\end{array}$ & 41 & 28 \\
\hline Details & $\begin{array}{l}\text { Requesting specific } \\
\text { information }\end{array}$ & 41 & 28 \\
\hline Feature & $\begin{array}{l}\text { Describing a specific } \\
\text { feature }\end{array}$ & 20 & 14 \\
\hline & & 151 & 100 \\
\hline
\end{tabular}

Table one shows that category 'feature' was under-represented, in comparison with the other categories. The implication of this is that the 'point' of the photographs was less about the capture of a particular feature and more about the use of this image to raise other questions. This, in part, shows that the participants were using the 'camera concept' in the manner in which it was described, i.e., not simply as a means for recording a specific feature but as the basis for subsequent question-asking. This might, at first, appear to be at odds with the claims made in section 3.1.1, i.e., that the images were of specific features. However, the role assumed by the participants was not simply one of capturing images but one of using the images to prompt subsequent questioning.

\section{DISCUSSION}

The study shows how a group of visitors were able to use the prototype to capture a set of images with the intention of supporting subsequent question-asking. Discussions with the participants suggested that the concept was interesting and that they would be willing to use a commercial version of the prototype (provided it was made smaller). For the purposes of sense-making, the following table shows how Weick's concept can be elaborated in terms of the study.

1. Grounded in identity construction - it is suggested that the participants performed two roles - that of 'recorder', in which (typically well-composed) images are captured to help remember the building and its environment, and that of 'historian', in which images are captured to prompt discussion of specific details, features and functions in order to raise questions about how people lived and worked in the Abbey;

2. Retrospective - the images were captured with an intention of both providing a memory of the visit and also to help remember the questions that were raised;

3.Enactive of sensible environments - the participants responded to specific features of the environment because these features draw their attention. Many of the images were of the presence of objects and these were captured to discuss their
Appearance. Other images were captured to reflect on Function of the objects and were equally likely to be images in which something was absent, e.g., of ruins;

4. Social- In this study, the social aspect was related less to the capture of the image and more to the notion that it would be used as the basis for subsequent discussion;

5. Ongoing - The sequence of image capture was strongly related to the route that the participant followed and, in part, reflects the movement around the site;

6. Focused on and by extracted cues - none of the images involved other people, which was partly a matter of the individual nature of the study but also implied that the nature of the visit was one of finding out about an historical site rather than simply 'being on holiday';

7.Driven by plausibility rather than accuracy - the selection of things to photograph was often prompted by questions relating to life in the Abbey, which could be seen as forming a reasonable explanation of the purpose of the Abbey and the lives of its inhabitants. There were very few images of aspects of the Abbey that did not conform to such a view.

The participants in this study produced sets of photographs that seemed to have three goals. First, images were captured to provide the basis for subsequent discussion. This was, of course, what we had asked them to do but it is interesting that they found this requirement not only easy to achieve but also appropriate to their visit. We interpret this as support for the notion that photography can provide a useful basis for sensemaking. We also note that the similarity of the photographs, both in terms of the content of the images and the location from which they were captured, implies a shared conception of how a visitor should view this site. This suggests that providing these captured images with additional commentary or text could be a viable means of developing tourist aids.

The second goal that we observed when participants took their photographs was as a record of their visit. Several of the photographs were, despite the fairly low resolution of the webcam we used, interesting and attractive images that could be looked at later to recall the visit. This is particularly apparent in the images in figure 1 and table 3. Thus, some of the photographs were captured to help remember the visit to the site.

The third goal was the movement around the site to find good vantage points. For the most part, photographs were taken at specific locations on a circular walk of the site. Two explanations of the relationship between walking the site and taking photographs were put forward. In one view, the act of walking supported the taking of photographs in that the person walked to a location that afforded a good vantage point for taking photographs. This would imply a plan to walk the site between 'good' locations, perhaps with the visitor deciding where to walk next after taking a photograph. In the other view, the visitor would walk until they reached a good location, and so photography was less planned and more opportunistic. Having taken a photography the visitor then changed direction and continued the walk. This is not to say that the two views are exclusive; it is plausible that the visitor will take photographs both opportunistically and also plan a walk to what looks like a good vantage point.

In conclusion, this paper has presented a pilot study of prototype technology that allows people to capture contextbased images of a visit to a museum. The manner in which this technology was used could be sufficiently explained using Weick's concept of sense-making. In relation to the broader 
aims of this project, we, therefore, suggest that image capture could provide an interesting and novel approach to supporting the definition, development and 'making' of sense of all manner of situations. Current work is exploring the use of similar technology for reconnaissance activity.

\section{REFERENCES}

[1] Aurhammer, M., Hanappe, P. and Steels, L., 2006, Integrating collaborative tagging and emergent semantics for image retrieval, WWW2006, May 2006, Edinburgh

[2] Baber, C., Cross, J., Smith, P. and Robinson, D., 2007, In J. Löffler and M. Klann (eds.) Mobile Response 2007, Berlin: Springer-Verlag Lecture Notes in Computer Science, 39-50

[3] Baber, C., Smith, P., Cross, J., Hunter, J. and McMaster, R. , 2006, Crime scene investigation as distributed cognition, Pragmatics and Cognition, 14, 357-385

[4] Baber, C., Smith, P., Panesar, S., Yang, F. And Cross, J., Supporting crime scene investigation, 2006, In N. BrynnKinns, A. Blandford, P. Curzon and L. Nigay (eds) People and Computers XX , London: Springer-Verlag, 103-116

[5] Bristow, H., Baber, C., Cross, J., Knight, J. and Woolley, S., 2004, Defining and evaluating context for wearable computers, International Journal of Human-Computer Studies, 60, 798-819

[6] Counts, S. and Fellheimer, E., 2004, Supporting social presence through lightweight photo sharing on and off the desktop, CHI'04, New York: ACM, 599-606

[7] Cross, J., Baber, C. and Houghton, R., 2005, Design of a minimal interface for two-way strategic information flow for urban operations, Digest of Papers of the $9^{\text {th }}$ International Symposium of Wearable Computers, Santa Monica, CA: IEEE Computer Society, 208-210

[8] Davis, M., Van House, N., Towle, J., King, S., Ahern, S., Burgener, C., Perkel, D., Finn, F., Viswanathan, V., and Rothenberg, M., 2005, MMM2: mobile media metadata for media sharing, CHI '05 extended abstracts on Human factors in computing systems, New York: ACM, 1335 1338

[9] Frolich, D. and Tallyn, E., 1999, AudioPhotography: practice and prospects, CHI'99 Extended Abstracts, New York: ACM, 296-297

[10] Golder, S. and B. Huberman (2006). "Usage patterns of collaborative tagging systems." J. Inf. Sci. 32(2): 198-208
[11] Gudivada, V. N. and Raghavan, V. V. (1995). Contentbased image retrieval systems. IEEE Computer, 28(9), 1822.

[12] Healey, J. and Picard, R.W., 1998, StartleCam: a cybernetic wearable computer, Proceedings of the $2^{\text {nd }}$ International Symposium on Wearable Computers, Los Alamitos, CA: IEEE Computer Society, 42-49

[13] Kato, T. (1992). Database architecture for content-based image retrieval. Proceedings of the International Society of Optical Engineering, USA, 3846, 112-123

[14] Larsen, J., 2006, Families Seen Sightseeing: performativity of tourist photography, Space and Culture, 8, 416-434

[15] Ljunblad, S., Hakansson, M., Gaye, L. and Holmquist, L.E., 2004, Context Photography: modifying the digital camera into a new creative tool, CHI'04 Short Papers, New York: ACM, 1191-1194

[16] Marlow, C., M. Naaman, et al. (2006). HT06, tagging paper, taxonomy, Flickr, academic article, to read. ACM Hypertext 2006 - Seventeenth ACM Conference on Hypertext and Hypermedia, Odense, Denmark, ACM Press

[17] Rader, E. and R. Wash (2006). Tagging with del.icio.us: Social or Selfish? Presented at CSCW 2006, Nov. 4-8 2006, in Banff, Alberta, CA. CSCW 2006, Banff, Alberta, CA.

[18] Risto Sarvas, R., Herrarte, E., Wilhelm. A. and Davis, M., 2004, Metadata creation system for mobile images, Proceedings of the 2nd international conference on Mobile systems, applications, and services, New York: ACM, 3648

[19] Urry, J., 2002, The Tourist Gaze, London: Sage

[20] Van House, N.A., 2007, Flickr and Public Image-Sharing: distant closeness and photo exhibition, $\mathrm{CHI}$ '07 extended abstracts on Human Factors in Computing Systems, New York: ACM, 2717-2722

[21] Weick, K.E., 1995, Sense-making in Organizations, London: Sage

[22] Wilhelm, A., Takhteyev, Y., Sarvas, R., van House, N. and Davis, M., 2004, Photo annotation on a camera phone, CHI'04, New York: ACM, 1403-1406

[23] Zhou, X., Zhang, Q., Zhang, L., Liu, L. And Shi, B., 2003, An image retrieval method based on collaborative filtering, Intelligent Data Engineering and Automated Learning, Berlin: Springer Lecture Notes in Computer Science, 1024-1031 